\title{
Gender Analysis of Social Health of Students
}

\author{
Anna Vladimirovna Vereshchagina ${ }^{1}$, Natalia Khalilovna Gafiatulina ${ }^{2}$, Aues Mukhamedovich Kumykov ${ }^{3}$, Oleg \\ Vasilyevich Stepanov ${ }^{4} \&$ Sergei Ivanovich Samygin ${ }^{5}$ \\ ${ }^{1}$ Institute of Sociology and Regional Studies, Southern Federal University, Rostov-on-Don, Russian Federation \\ ${ }^{2}$ Southern Federal University, Rostov-on-Don, Russian Federation \\ ${ }^{3}$ Kabardino-Balkaria State University, Nalchik, Russian Federation \\ ${ }^{4}$ Southern Federal University, Rostov-on-Don, Russian Federation \\ ${ }^{5}$ Rostov State University of Economics (RSUE), Rostov-on-Don, Russian Federation \\ Correspondence: Anna Vladimirovna Vereshchagina, Pushkinskaya street, 160, Rostov-on-Don, 344005, Russian \\ Federation. Tel: 78-6-3264-1755. E-mail: anrietta25@mail.ru
}

\author{
Received: March 30, 2015 Accepted: April 20, 2015 Online Published: May 14, 2015 \\ doi:10.5539/res.v7n7p223 URL: http://dx.doi.org/10.5539/res.v7n7p223
}

\begin{abstract}
The gender dimension is based on the idea that not the physical or biological differences between the masculine and feminine are significant, but the sociocultural meaning attached by the society to these differences. Gender specification of the sex is exposed quite early, but sometimes it is not noticed and the society, accordingly, does not pay much attention to it in the context of socialization of young people. One of the main reasons of the not entirely satisfactory health status of the youth in all its sides - physical, mental, and social —is at the root of this phenomenon. Despite the fact that at present, the findings of the social determination of the health status, its gender differentiation are generally recognized, the study of Russian students and their social health from the gender perspective has not yet become very popular in the sociological science. In this regard, the authors believe that at the level of sociological reflection, the development of a gender approach to the study of the social health of students, in the light of which this article analyzes the dependence on gender of the social health of students of the Southern Federal University, acquires critical importance.
\end{abstract}

Keywords: social health, students, gender differentiations, gender stereotypes, subjective health indicators, the Southern Federal University

\section{Introduction}

The study of social health of students in the social sciences and humanities is based on different methodological approaches that allow assessing the diversity of views on its nature from different viewpoints. Herewith, modern scientific studies demonstrate permanently growing interest in the study of gender relations and dependence of health on the gender, and in incorporating the gender approach to intellectual comprehension of the "social health" category. Sociological study of the social health of Russian students is of great practical, socio-medical, and public importance. Today's youth is to implement such important social functions of the society as the professional and labor function, as well as the reproductive, intellectual, sociocultural, and moral functions. Russian students, as a specific population group, are very responsive to any processes taking place in the modern society. And since the social transformations taking place in the Russian society for over 20 years have significantly changed the social space and along with it the economic, socio-stratificational, cultural and national, ideological, and gender relations, it is natural against the background of these transformations that changes are observed in the pattern of the social health of young people.

The inequality of social health of students is based on the benefits or, conversely, deprivations associated with the distribution of wealth, power, prestige, i.e. with the attributes of the social hierarchy, of which gender hierarchy is a variety. Currently, the need for a brand new coverage of gender aspects of health has been clearly delineated due to the gender-based needs in the social health of the Russian students. The objective conditions of the state of social health of the modern students require creating a mechanism for effective impact on gender processes related to the improvement of the nation and increase in its spiritual and physical potential. The weak theoretical elaboration and insufficient specification of the social side of health were mentioned by I. Mc Dowell 
and C. Newell who pointed to the much lesser number of developments in the field of social health compared to the physical and mental health fields (McDowell \& Newell, 1997). Despite the practical relevance of gender studies in the field of social health of students in contemporary Russia, the number of research papers in this field is very small, which provides many opportunities for research on this issue.

Thus, the purpose of this article is to determine the level of social health among students and find gender-based differences in the mechanisms of formation of social health groups and in the indicators of the social health of young people.

\section{Research Methodology}

Gender-based differences of students in the attitude to health and characteristic of social health are formed under the influence of a number of sociocultural factors, namely: the socioeconomic, environmental, cultural, historical, psychosocial, and behavioral factors. In addition, the social health of students is undoubtedly influenced by gender socialization, which can be defined as the process of learning norms, rules of conduct, stereotypes, and social attitudes in accordance with the cultural perceptions of the role, purpose, and status of men and women in the society (Yaishnikov, 2013). In the student community, the socialization process has peculiarities, including the gender-based ones, which we will try to show based on the results of the author's sociological empirical research on the topic "Social health of students: gender-based analysis" conducted in September and October 2013 in Rostov-on-Don. The research objects were students of the Southern Federal University (SFU) divided into two groups by gender. The main method to identify gender dependence of social health is the method of sociological survey. The sample population $(\mathrm{N})$ amounted to 782 persons. A sociological survey studying the social health of students was conducted by the method of random selection in various faculties of the Southern Federal University (hereinafter-SFU). The survey covered evenly all age groups of students ranging from 17 to 22 years.

For more in-depth information on the topic, an expert survey was carried out in the form of interviews (N-36 persons). The experts were SFU teachers and specialists of the Ministry of Health and Education of Rostov-on-Don. The method of poly-structured interview was used, in which the first part was biographical, the second included questions associated with identifying personal opinions of experts on the issues of social health of today's youth. The survey was conducted in autumn 2013. This body of empirical sources in conjunction with the results of research carried out by other domestic scientists and sociological centers for the health issues of the Russian youth became the basis for obtaining empirically sound knowledge of gender dependence of social health of Russian students.

\section{Results}

The conducted sociological study confirmed the importance of further study of social health of students from the perspective of the gender-based approach. Based on the 2013 sociological research conducted at the Southern Federal University and the analysis of the obtained data, we have drawn the following conclusions:

-Education at a higher educational institution contributes to changing the subjective well-being and social health of students. Female students demonstrated the highest emotional stress and social pessimism.

-More than half of students (boys and girls) generally had satisfactory social health. However, in the course of study from year 1 to 4 , there is a decrease observed in the number of young men with good social well-being and high activity.

- The incidence indicators of students have gender-based differentiation: the incidence of female students is slightly higher than of male students.

- Social health is determined largely by subjective factors expressed in self-assessment of social well-being;

- Most students predominantly have pessimistic social well-being in different variations, which generally shows a tendency of social health deterioration. Herewith, young women compared to young men are more pessimistic in their assessments, while young men are more optimistic in the subjective assessment of their health.

-A significant part of the male students had a medium level of anxiety with a downward trend. Nearly half of female students at the beginning and end of the study at a higher educational institution have a medium level of anxiety with a tendency to its increase.

- Gender differences are particularly obvious in the mechanisms of formation of groups of social health at the analysis of conscious social well-being. Following the results of the sociological survey, we identified four groups of respondents who had differences among them in terms of social health and demonstrated persistence of gender stereotypes. These groups were designated as "positivists", "pessimists", "indifferent", and "marginal". 
The social health of students is largely determined by the state of their emotional sphere and the gender-based and personal attitudes.

\section{Discussion and Results}

The student period of life is described by changes in the social status, assimilation of a new social role by young people. In the definition of students, the following characteristics can be singled out that distinguish them from other groups: firstly, the age limits of the youth age; secondly, the specific features of the social status; thirdly, the role functions and features of gender behavior; fourthly, gender self-identification and self-determination of students as a social group. The student age is a special life stage mediating transition of a young person into adulthood. Expansion of the range of interpersonal interaction and its intensification are typical of this period. Informal communication is most important for students and is reflected on the state of their social health, as this communication optimizes the state of the psycho-emotional sphere and acts as a support in difficult circumstances.

In order to analyze further the obtained results, we need to distinguish the concepts "health", "social health" and "social well-being". The starting point for studying the phenomenon of "health" is the definition given by the World Health Organization, according to which health is interpreted as an integrated indicator of the state of an individual, as a state of "complete physical, mental, and social well-being". Such conditionality of human nature determines the multidimensionality of the health category, allowing to talk about somatic (physical) and social aspects of health (Laslett, 1995), i.e. health is understood "not from the narrow medical and biological point of view, but broader: the social and psychological context is taken into account" (Goldsmith, 1992). This brings us to important distinction between the objective and subjective components of health" (Ramon, 2012). An objective approach to health involves the assessment of health by an external observer (expert) within specialized medical and social surveys (Greer, 2006). And a subjective approach reflects the feelings, internal attitudes, and opinions of the individual himself (Cockerham, 2000).

Let us consider the category of "social health" of youth, which has very recently been introduced into scientific use and which is generally understood as the influence of social factors on the physical, mental, and moral health of an individual. Various social factors generally have both positive and negative effects on the health of a young person (Whitehead, Dahlgren, \& Gilson, 2001).

Social health in the author's interpretation is considered as an indicator of social well-being of an individual, the extent of his adaptation and social activity. The role of social health, in our view, lies in its regulatory function. Becoming the behavior motive, it can be expressed in various forms of activity or inactivity of students. In contact with the society, reproduction of the system of subjective sensations occurs, which indicates a certain degree of social and psycho-physiological comfort (Neilson, 1998).

In general, the concept of social health is considered by sociologists as a state of an individual, a group, a society, which are normal in terms of basic status parameters, namely: the physical, psychological, spiritual, sociocultural, and socioeconomic parameters. Due to the stability of individual status characteristics of an individual, as a result of the effect of the integrating and socializing functions, we can assess the social norm of an individual, his social health, and social well-being (Marshall et al., 2014).

By its nature, social health of young people has cognitive, axiological, emotional-sensory, and behavioral aspects. The cognitive aspect is related to rational learning of the surrounding social reality, the axiological (evaluative) aspect-with the mechanisms of evaluation and self-evaluation, and the sensual aspect-with emotional experiences and attitudes towards a particular situation. As for the behavioral aspect, it affects the activity of a young person aimed at self-preservation or self-destruction (Gafiatulina, 2013).

The value-related component of social health manifests itself in comparison of the young persons' knowledge and understanding of the society and of themselves with their own needs and interests. This component is directly associated with evaluation and self-evaluation. The main problem here concerns the extent, to which their social and value-related references correspond to the value system of the society. We believe that self-evaluation is what exposes the subjective nature of social health of a young person, as the nature and level of the self-evaluation are entirely dependent on the person's ability to assess objectively his own actions, deeds, and thoughts. Thus, self-evaluation acts as the base and the main mechanism of formation of the subjective aspect of social health - the social well-being.

Speaking about the gender aspect of the valuable component of social health, we find it important to note that the value references are, on the one hand, a product of socialization of young men and women, i.e. assimilation of sociocultural traditions, moral, political, aesthetic ideals, and enduring regulatory requirements of the society. On 
the other hand, the value references in the field of social health, being a reflection of the determining interests of young people, express their subjective social position. Formation of proper attitude to social health in the general system of values means the formation of personality of a young person as an active subject of the social reality. It is the basis of value-related consciousness of young men and women and affects their behavior. "Value references act at the level of both consciousness and subconscious, determining the direction of willpower, attention, intelligence" (Kravchenko, 2008).

The obviousness of gender-based individual self-assessments of health was mentioned by modern scholars V. A. Medik and A. M. Osipov. According to the results of their research conducted in the Novgorod State University, young women are much less likely to feel complete satisfaction of their own health than young men. $33 \%$ of young men and just $21.5 \%$ of young women assess their health state as "good". But with regard to awareness of the presence of chronic diseases, young women are relatively better informed (20.3\%) compared with young men (9.8\%) (Medik \& Osipov, 2005).

In our opinion poll among students of SFU aiming to measure the level of social health, we formulated the question as follows: "How do you assess the state of your social health?" The gender-based distribution of answers to the question is as follows: $13.1 \%$ of young men and $12.5 \%$ of young women assessed the state of their social health as "very good". $37.8 \%$ of young men and only $25.9 \%$ of young women considered it "good." $47.9 \%$ of male students and $56.3 \%$ of female students, respectively, assessed the level of their social health as "average, neither good nor bad." $1.3 \%$ of young men and $5.4 \%$ of young women said they had poor social health.

Based on the analysis of the obtained data, the subjective health assessment clearly reflects the gender dependence of the social health. In particular, young men are more optimistic in the subjective assessment of their health than women are: $48.5 \%$ of young men said they had good health, and only $32.4 \%$ of young women supported this point of view. Moreover, $56 \%$ of young women and $36.8 \%$ of young men believed that their health condition was satisfactory (neither good nor bad). There is an obvious pessimistic point of view of young women in assessing their own health.

This fact is probably associated with earlier primary socialization of young women compared to young men and slightly increased responsibility for health in the event of its temporary loss.

When analyzing the responses to the poll question "Do you have a side job?", we found that $44.7 \%$ of young men occasionally work, and the share of those who have permanent job is $5.6 \%$. Accordingly, $38.8 \%$ of young men indicated that they did not have any side job, and the share of young women who did not work was $78.8 \%$. Over $27 \%$ of young men and only $4.5 \%$ of young women were engaged in physical, service labor that did not relate to their specialty. This situation is largely due to the fact that the modern Russian society continues to reproduce traditional gender stereotypes. The peculiar features of the existing regional labor market, namely the limited choice of employment for young women, allows us to explain the fact that there are fewer female students earning additionally than male students. Young men are more likely to believe that they manage to combine work and study normally (32.2\%) than young women, and the share of young women who share this point of view is just $12.8 \%$. In addition, young men are ready to work a lot to earn "good money". Respectively, their anxiety for employment increases from $24.4 \%$ in the first two years of study to $44.4 \%$ in the last year of study.

Employment inevitably entails for many young people changes in life patterns, the conditions and intensity of the labor and (or) educational process, the regime and quality of nutrition, and sometimes moving to another place of residence. The consequence of all of the above will be a need for appropriate adaptation to new environmental factors of socio-hygienic, psychosocial, economic, climatic, and other nature. None of these factors can affect the quality of the social health of students.

This situation reflects the current state of our society, when success is achieved through a high level of social and economic activity that above all requires good health. If the financial capabilities guaranteeing success are limited, the instrumental value of health as a means to achieve other goals increases, which contributes to more intensive exploitation of health.

In the modern society, the responsibility of a person for his own health, that is, the behavioral aspect of social health, is of paramount importance. This is due to the fact that in the event of physical and social disadvantage, avoidable subjective factors that can be eliminated to create a balance between the social and anthropogenic environment and the biological structure of the human organism are most important. One of the indicators that identify the behavior of a young man, contributing to the preservation of his social and physical health is his medical activity. For the first time this category has been described by Yu. P. Lisitsyn in 1987 as part of the 
socio-sanitary science. The medical activity is understood as the attitude to health, abidance by various medical and social requirements, social and health standards, and other human activities, groups of population related to health. According to Yu.P Lisitsyn, social health reflects a certain state of society, in which every citizen is given the opportunity to live a healthy lifestyle (Lisitsyn, 1999). The main condition of medical activity is the understanding by a young person of the enduring value of health, the need for personal involvement in its preservation and promotion, even before the actual deterioration of health, either physical or social.

According to the empirical data obtained by us, most students (59.2\%) see a doctor 1-2 times a year; $24.7 \%$ - once in several years; $11.6 \%-2-5$ times a year; $3.8 \%$ - more than 6 times a year. Compared with young women, young men are much less likely to seek medical advice. The frequency of visits also significantly decreases over age: the share of respondents who see a doctor once a year increases, and the share of those applying 3-5 times a year, on the contrary, decreases. We assume that during the training, students accumulate a certain level of medical and social knowledge often allowing to determine the tactics in relation to their own health.

As the first and the main reasons for non-abidance by doctor's recommendations, SFU respondents referred to the lack of time (43.8\%) citing the fact that in the case of treatment, they have to miss classes and then catch up. This is the dominant motive of young women. The second indicated reason (27.9\%) is that doctors give many prescriptions and people feel lazy to abide by them. Some respondents believe that "everything will eventually go away by itself." Almost one in five (19.5\%) did not meet the recommendations due to lack of money. Herewith, women are more likely to indicate this cause than young men are.

In addition, female students more often than male students indicate the poor quality of medical services provided at the higher educational institution, which is also a factor of lack of attention to their social well-being and overall health.

Gender studies of differences between the "masculine" and "feminine" cognitive aspects of social health are very heterogeneous and, as a rule, are also based on gender stereotypes, which are described as a simplified way of behavior of men's and/or women's traits. These stereotypes are very stable and are manifested in all spheres of human life: self-awareness, interpersonal communication, interaction between groups, social health (Workshop, 2003). According to our surveys, women's social health is considered more situational and changeable due to the initial dependence of the state of health of young women on emotional contacts and interpersonal relationships. Evaluation of the psycho-emotional sphere of students showed that they had a high level of anxiety. More than half of students of both sexes have either inflated or low self-esteem.

Also, an interesting opinion is the opinion popular in the youth community that the care of social health is primarily a women's issue. According to gender stereotypes, the majority of young men have shown little interest in social health, moreover, they do not have a clear idea about it, giving preference to physical health, as a symbol of masculinity. There were more associations for the concept of "social health" given by females. Women's answers to the question "What is social health? How do you understand this term?" are more emotional, bulky, often are associated with a particular situation, and generally have a clear focus on the value of personal well-being (love, family, beauty, wellness, pleasure). This reflects the gender-based socio-psychological peculiarities of young women. In the view of young men, social health is attributed with the so-called active and creative characteristics (activity, self-reliance and confidence, the ability to grow and develop socially).

Our results demonstrate high psycho-emotional stress and social pessimism on the part of females, which, in turn, cannot but affect the qualitative and quantitative characteristics of population reproduction. Lately, only every seventh young woman $(14.3 \%)$ sees her future with optimism, and $43.7 \%$ note they are concerned about the prospects of their lives. Moreover, in comparison with young men, the high percentage of young women concerned with their professional future is present in all age groups. Thus, we have found that there are two stereotypes regarding gender preferences of employers. The first stereotype popular among students says that the female workforce is less profitable and more costly. In many ways, this stereotype is based on the idea of the currently effective legal benefits and guarantees for working women. Another stereotype determinate existence of the employer about the specific "male" and "female" occupations. At the same time, $47.2 \%$ of SFU students surveyed were sincerely convinced that such differentiation is predetermined by nature. Young women believe that traditionally they are assigned the issues related to education, culture, and health. Their share, according to various estimates, in these sectors ranges from $67 \%$ to $80 \%$. As evidenced by our study, namely female students do not build any illusions or nourish hopes about their future. In the Southern Federal University, the share of such young women is $37.3 \%$, and the share of such young men is slightly higher- $43.7 \%$, which, in turn, affects the background of social well-being and influences on the social side of health. The share of young women 
almost satisfied with their present life and evaluating their social health as rather well, is quite small (3.7\%), and one in three suffers the subjective feeling of dissatisfaction and social disadvantage. Among young people dissatisfied with their lives and health state, we can note the appearance of negative characteristics of social health among first year female students compared with students of senior courses.

According to experts who we interviewed, this situation of dissatisfaction with their present life and the sense of social disadvantage is due to the financial and psychosocial problems in connection with their studies at the university, the combining of work and study, family relationships, the sense of loneliness. But not all experts keep to such a point of view on this issue. Some experts point out that a lot depends on the temperament and temper of the person. Experts also point out that one of the risk factors for adverse impact on the health of students of the Southern Federal University are the adverse learning conditions due to an increase in the classroom academic load. This increase is due to several reasons of organizational nature: moving from faculty to faculty, pauses between classes, uneven distribution of the teaching load by days of week. Besides the maximum part of the load includes independent work during extracurricular time. This is confirmed by a survey of students, according to which their load with self-guided work reaches 6-7 hours. As shown by the survey, about $44.7 \%$ of students find the academic load very hard. At the end of school day, $56.9 \%$ of respondents feel socially unwell. At the same time, at the end of the school week, $69 \%$ of students demonstrated persistent changes in their social behavior: $32.6 \%$ of young men became aggressive, $24.3 \%$ of young women-more vulnerable and sensitive, $16.9 \%$ - calmer, and $17.1 \%$ - apathetic.

According to the results of our study, incidence rates difference is gender-dependent: the incidence of female students is slightly higher than of male students, which is consistent with the data of other authors. According to experts, the academic work of students is accompanied by stress situations during tests and exams, which, one way or another, affect the psychosocial and physical health of young people. Experts also believe that the costs of organization of learning activities of students in the global growth of professional information to be assimilated substantially affect the lifestyle of students. As a result of the conducted sociological survey of students and interviews with experts, we identified four groups of respondents differing in social health and demonstrating persistence of gender stereotypes.

The first group - "positivistic" students. It is important to note that in this group of SFU students, male undergraduates prevail significantly, who have found a job somewhere and combine education and work. It is worth noting that the students of this group generally showed high activity and good adaptation to the university study (the need to search for information, autonomy, etc.). They do not find it difficult to allocate their time intelligently (to combine education, work, and leisure time). Most of the female students who we placed in the first group consider that the load at the university is not significantly different from the load at school. In addition, this group of students is less concerned about financial and housing problems, because the majority of them are local citizens.

Representatives of this group exhibit optimistic assessment of social health and its prospects, and mainly rely upon themselves. They expect the people around to "create conditions" for and "avoid interfering" in the practice of personal social healing. Their value orientations are usually built on achieving financial well-being and securing a certain social status. This manifests itself for example in phrases such as: "young people need a guarantee of security, and they can handle everything else on their own", "it is necessary to create conditions for young people to make money, and social health will improve automatically", "if the person works hard, he will always feel good", "one must set goals and achieve them". Such statements give us every reason to believe that currently, young people virtually do not tend to rely on luck or fate in achieving a high level of health, but more on themselves and their own ability. Although these statements, in our opinion, demonstrate consumer attitude to health, its instrumental rather than fundamental value.

The second group - "pessimists". Representatives of this group are pessimistic about their health and social position in the society as a whole, considering that it is unlikely that anything will change through their own efforts. They hope for "acceptable sport and recreational activities", for "change in the youth policy in the health sector." In other words, students in this group are focused on the impact from the outside. They express passivism, which demonstrates the stereotype of femininity that "Femininity is seen as "passive and reproductive principle", which manifests itself in the expressive personal characteristics, such as addiction, caring, anxiety, low self-esteem, emotionality" (Workshop, 2003). Therefore, young women prevail in this group. Herewith, a characteristic singularity of the age criterion has been revealed that the number of senior female students is more than the number of junior female students. In addition, members of this group are inactive and much less adapted to the singularities of studying at SFU. There is a large share of female students who believe that the academic load in this higher educational institution is higher than in other educational institutions. They experience 
considerable difficulties in the distribution and combination of educational and leisure time. In this group, there are many foreign students living in SFU dormitories or renting rooms (apartments). Therefore, it is quite understandable and logical that the representatives of the "pessimists" are increasingly concerned about the housing and financial problems. In the social interaction with fellow students and teachers, about $32.5 \%$ of the respondents have difficulties in communicating, which, as we understand it, evidences a low level of social health.

The third group - "indifferent". Representatives of this group are distinguished by the indifferent views on social well-being; they have little interest in their health. For them, the main issue is to have a source of livelihood, and the state of social health is not so important. It is interesting that the representatives of the designated group have shown minimal social demands, and their personal ambitions and aspirations are also minimized. This is seen, for example, in such expressions as: "Why improving anything if I feel good without it?", "if the nature has given good or bad health, I can change nothing", "you can live with any level of health, the main thing is to have something to eat and to wear."

As for the level of adaptation in the academic environment of SFU, the representatives of this group identified an average level of adaptation to the learning process. Students in this group are not particularly concerned about the financial and housing problems, as they do not interfere with their studies, do not affect their mood and well-being in general. In this group, gender differences are underrepresented, as approximately the same number of respondents of both sexes was revealed.

The fourth group - "marginal". Members of this group are characterized by the fact that they do not have a clear understanding of their own social health state and their value orientations in this field, they demonstrate opposite attitudes in the perception of social health and social well-being. This fact is highlighted with, for example, the phrases: "strong youth policy" and "freedom of lifestyle choice", "the right for personal self-determination" and "protection of the interests of health". On the one hand, these young people are not very happy with the state of their social health, but on the other hand, they cannot indicate clearly and reasonably, what they would need in order to optimize their health. Their value orientations are directed to the expectation of sudden "luck" when all the problems go away by themselves and all will be well. We can say that a kind of youthful infantilism determines their beliefs and behavior. For example, the following statement is remarkable: "It would be nice if my rights were defended, my social health was strengthened, I could gain much, and it would not affect me". The main population of this group are young students of the first and second years of study at SFU, aged between 17 to 20 years, with the share of males slightly higher than females.

The representatives of the fourth group demonstrate social passivity and a low level of adaptation. They fail to adapt to the demands of teachers of SFU. It is difficult for them to master the rules of study at the faculty. Students in this group sometimes do not know who to ask for help on a particular issue, and fail to adapt to the rational combination of educational and leisure time.

\section{Summary}

There are plenty of grounds for adverse social health of today's youth (issues of social adaptation, financial well-being, getting a decent education, employment, issues of qualified social, legal, and medical aid).

Social health of students is a result of its socialization not only in a higher educational institution, but also in the family, which is always responsible for the spiritual and physical state of young people, formation of high-value of health and mechanisms of self-preservation behavior of the youth.

Deterioration of social health of students is a threat to the Russian national security, because in the near future, this part of the youth will occupy key positions in the system of social relations. Thus, this problem is a problem of not only students, but also the entire Russian society, which has no ideology of health.

\section{References}

Cockerham, W. (2000). Health Lifestyles in Russia. Social Science and Medicine, 51. http://dx.doi.org/10.1016/S0277-9536(00)00094-0

Gafiatulina, N. H. (2013). Health-saving models of professional socialization of students in the circumstances of social uncertainty. Inzhenerny Vestnik Dona, 26(3). Retrieved from http://www. ivdon.ru/magazine/archive/n3y2013/1824

Goldsmith, S. (1992). The Status of Health Indicators. Health Service Reports, 87.

Greer, A. (2006). The Measurements of Health in Urban Communities. Journal of Urban Affairs, 8.

Kletsina, I. K. (Ed.). (2003). Workshop on gender psychology. St. Petersburg: Piter. 
Kravchenko, L. A., \& Isaeva, L. A. (2008). Gender specificity of value orientations and motivational attitudes in employment (regional aspect). Sotsialno-gumanitarnye Znaniya, 8.

Laslett, P. (1995). A new division of the life course. In B. Davey, \& G. A. Buckingham (Eds.), Health and Disease. Philadelphia: Open University Press.

Lisitsyn, Y. P. (1999). Social care (medicine) and health care organization. Moscow: NGO "Medikoservis."

Marshall, B. D., Astone, N., Blum, R.W., et al. (2014). Social Capital and Vulnerable Urban Youth in Five Global Cities. The Well-Being of Adolescents in Vulnerable Environments Study. Journal of Adolescent Health, 55(6), 21-30. http://dx.doi.org/10.1016/j.jadohealth.2014.08.021

Medik, V. A., \& Osipov, A. M. (2005). "University students' community". In Lifestyle and health. Moscow: "Logos".

Neilson, E. (1998). Health Values: Achieving High Level Wellness-Origins, Philosophy, Purpose. Health Values, 12.

Ramonov, A. V. (2012). Analysis of the health status of the population of Russia with integral indicators. Sotsiologicheskye Issledovaniya, 3.

Samygin, S. I., \& Vereshchagina, A. V. (2014). Family and social security. Gumanitarnye, Sotsialno-ekonomicheskiyei Obshchestvennye Nauki, 2.

Whitehead, M., Dahlgren, G., \& Gilson, L. (2001). Developing the policy response to inequities in Health: a global perspective. In Challenging inequities in health care: From ethics to action (pp. 309-323). New York: Oxford University Press. http://dx.doi.org/10.1093/acprof:oso/9780195137408.003.0021

Yaishnikov, A. Y. (2013). Gender features of socialization of students of higher educational institutions of the Rostov region. Gender relations in the socio-cultural environment: Collection of scientific articles. In Proceedings of the Jubilee X International Gender Readings "Gender Relations in the Socio-Cultural Environment" (pp. 293-296). Rostov-on-Don: The Publishing House of the Southern Federal University.

Zhuravleva, I. V. (2012). Why is the health of Russians not improving? Vestnik Instituta Sotsiologii, 6. Retrieved from http://www.vestnik.isras.ru

Zubok, Y. A., \& Chuprov, V. I. (Eds.). (2008). Encyclopedic Dictionary. In Sociology of Youth (p. 610). Moscow: Academia.

\section{Copyrights}

Copyright for this article is retained by the author(s), with first publication rights granted to the journal.

This is an open-access article distributed under the terms and conditions of the Creative Commons Attribution license (http://creativecommons.org/licenses/by/3.0/). 